\title{
Current Trends in Phonology: Theoretic Account of Amharic Spirintization
}

\author{
Tilahun Negash*, Yoseph Zewdu, Haile Kassahun \\ College of Social Sciences and Humanities, Debre Markos University, Debre Markos, Ethiopia \\ Email address: \\ tntilingp@gmail.com (T. Negash), Yosephzewdu@gmail.com (Y. Zewdu) \\ ${ }^{*}$ Corresponding author
}

\section{To cite this article:}

Tilahun Negash, Yoseph Zewdu, Haile Kassahun. Current Trends in Phonology: Theoretic Account of Amharic Spirintization. Humanities and Social Sciences. Vol. 7, No. 3, 2019, pp. 115-120. doi: 10.11648/j.hss.20190703.14

Received: January 28, 2019; Accepted: April 8, 2019; Published: July 4, 2019

\begin{abstract}
This paper intends to illustrate an analysis about one of the common phonological process known as spirantization in Amharic in the framework of Optimality and Feature Geometry. The theoretical models we have been assuming - known as the linear theory of representation-was quite successful in explaining a number of facts about sound systems. A defining characteristic of the theory is the view that segments are matrices of feature values, where every segment has a specification for each of the two dozen distinctive features. There were, however, phonological realms which the theory had largely ignored, and that were spirintization and assimilation. The process of these phonological processes in Amharic language can be shown and represented in Optimality Theory and Feature Geometry more clearly than in linear phonology. The method used in this research is analytical-descriptive. Six native speakers who were selected from different age groups that ranges from 30 to 50 and different educational levels were interviewed. Furthermore, free conversation and life stories were also included in the corpus. The data gathered is phonemically transcribed following the IPA conventions as revised to 2005 and analyzed using Optimality and Feature Geometry. Amharic, which is one of the most important languages of Ethiopia, is mainly spoken in Amhara regional state of Ethiopia. The language belongs to Transversal South-Ethio-Semitic group of the Afro-Asiatic language phylum. According to the 2007 Population Census, Census (2008) report, there are around 22 million Amharic native speakers and additional 7 million second language speakers. The language spoken in this region can be divided into four general regional dialects. The investigation of the major dialectal variations and isoglosses of Amharic are scanty. The available literature identifies four major dialects of Amharic: Gojjam, Gonder, Shewa and Wollo. Although the isoglosses and internal dialectal variations are hitherto not clearly established, the literature agrees on the mutual intelligibility among the dialects of this language. In Amharic, there are two consonants which engage in spirantization process. These consonants include /b, k / which are changed to the fricatives. Lenition patterns are expressed in terms of conflicts between the effort minimization constraint, LAZY, and on the other hand a class of lenition-blocking constraints. Spirantization, for example, is analyzed in terms of rankings where LAZY dominates IDENT (x). Under the opposite ranking, spirantization is blocked. There are three major feature groups, laryngeal features, manner features and place features, which Clements calls Class Nodes. In spirantization process, in the manner node, the feature (continuant) is added to a stop consonant, producing a fricative at the same place.
\end{abstract}

Keywords: Amharic, Feature Geometry (FG), Lenition, Optimality Theory (OT), Spirantization

\section{Introduction}

The classic version of Optimality Theory, first described in detail by Prince and Smolensky [15] is a phonological framework that privileges the simultaneous satisfaction of multiple, violable constraints by phonological representations over the gradual construction of correct representations from given inputs. At its core, an OT grammar implements a search procedure that finds the surface form that is most compatible with the relevant underlying representation, given the specific properties of the particular language. In OT, these language-specific properties are encoded as a series of rank able, violable constraints. The "creation myth" of Optimality Theory often sees its flowering as the culmination of 
dissatisfaction with the input-oriented, process-heavy framework rooted in the SPE model. In this view, rule-based approaches are vitiated by an emphasis on the properties of the input, which trigger the (non-) application of rules, and formal difficulties with expressing generalizations about the output of rules.

The purpose of the present study is to provide an overview about one of the common phonological processes in Amharic, spirantization, and to review the theoretical implications of this process. Amhara region is located in the center of Ethiopia. Northward, it is bounded to Tigray, Eastward to Afar and Somali, Southward and Westward to Oromia regional states. Speakers in this region can be divided into four general dialects: Gojjam, Gonder, Shewa and Wollo.

Fricative is a term used in the phonetic classification of consonant sounds on the basis of their manner of articulation, also sometimes called spirant; it refers to sounds made when two organs come so close together that the air moving between them produces audible friction. There is no complete closure between the organs (in which case a plosive articulation would be produced): there is simply a stricture, or narrowing. The fricative manner of articulation produces a wider range of speech sounds than any other. They are sounds with a potential for considerable duration (e.g. s-s-s), and, from this point of view, the opposite of fricative (i.e. a continuant sound lacking friction) is called a frictionless continuant. The term spirantization is sometimes used for the process of deriving a fricative from some other type of articulation. Spirantizaton refers to a process in which plosives become fricatives, and this often occurs in environments containing vowels. In particular, it is common for Consonants between two vowels and consonants in the presence of high vowels.

Lenition is a term used in phonology to refer to a weakening in the overall strength of a sound, whether diachronically or synchronically; opposed to fortition. Typically, lenition involves the change from a stop to a fricative, a fricative to an approximant, a voiceless sound to a voiced sound, or a sound being reduced (lenite) to zero. Two types of weakening are distinguished:

(a) Consonant weakening (also lenisization): this denotes a weakening of consonant strength (through a reduction in air pressure and muscle tensionor an increase in sonority) to the complete loss of a segment.

(b) Vowel weakening: this is a term for all processes that lead to a weakening of the articulatory movement in the sense of an increasing centralization of vowels and finally a total loss of the vowel.

Lenition processes increase a segments' sonority and fortition processes decrease it. Sonority is a term in auditory phonetics for the overall loudness of a sound relative to others of the same pitch, stress and duration. Sounds are said to have an 'inherent sonority', which accounts for the impression of a sound's 'carrying further', the optimality approach advocates articulatory effort as the motivation of lenition and fortition. For instance, fortition is effort-based and driven by a natural need to maximize articulatory effort. Within the NP framework, the lenition/fortition definition is based on the needs of the speaker as well as the listener and offers an operational procedure: if the phonological material is deleted for the benefit of the speaker, it is a lenition; when the material is added for the sake of the listener, it is a fortition. In this paper, we are going to study spirantization in Amharic dialects according to the theoretical framework of Optimality and Feature Geometry to answer the following questions:

1. In which one of the consonant of Amharic dialects, the spirantization process is seen?

2. In which contexts do the spirantization processes apply in this dialect?

3. How can we analyze the data in OT and FG theories?

\subsection{The Consonant System of Amharic}

Before the representation of the data, it seems necessary to discuss about consonants and vowel phonemes of Amharic language. The phonological system of Amharic consists of 24 consonants and 7 vowels. the occurrence of $/ \mathrm{p} /, / \mathrm{p} /$ and $/ \mathrm{v} /$ are restricted to loan words from the European languages, particularly Greek and English [12]. Thus, they are not considered the phonemes of the language in this article. The consonant inventory of Amharic can be classified as follows: six stops /b, t, d, k, g, P/; three ejectives $/ \mathrm{t}^{\prime} \mathrm{t} \int$, $\mathrm{k} /$; six fricatives/f, s, $\mathrm{z}, \int, \mathrm{z}, \mathrm{h} /$; two affricates/dt, t $\mathrm{f} /$; three nasals $/ \mathrm{m}$, $\mathrm{n}, \mathrm{j} /$; one lateral $/ \mathrm{l} /$; one trill $/ \mathrm{r} /$ and two glide $/ \mathrm{w}, \mathrm{j} /$.

\subsection{The Vowel System of Amharic}

Among the simpler vowel systems in the languages of the world is the Amharic vowel system. It is composed of seven vowels. These seven vowels are generally recognized as: two front vowels /i/, /e/, three central vowels /i,ä, a/ and two back vowels $/ \mathrm{u} /, / \mathrm{o} /$. The following table illustrates the vowel system in Amharic. Vowel length is not phonemic in Amharic language.

Table 1. Vowel system of Amharic.

\begin{tabular}{llll}
\hline & Front & Central & Back \\
\hline High & $\mathrm{i}$ & $\dot{\mathrm{i}}$ & $\mathrm{u}$ \\
Mid & $\mathrm{e}$ & $\mathrm{a}$ & $\mathrm{o}$ \\
Low & & $\mathrm{a}$ & \\
\hline
\end{tabular}

\subsection{Theoretical Framework}

\subsubsection{Optimality Theory}

The theoretical frameworks used in this study are Optimality Theory and Feature Geometry (OT and FG, hereafter). OT came into existence in early 1990s, mainly focusing on contemporary phonological studies [14] and [9]. This theory was developed as a response to a "conceptual crisis at the center of phonological thought" [14] concerning the role of output constraints. It was also inspired by the concepts of neural networks, as shown by the significance of ideas, such as optimization, parallel evaluation, competition, and conflicting constraints which are also present in the 
framework of OT. OT is often considered as a development of generative grammar and the successor of the harmonic grammar developed in 1990s [14].

In a typical OT analysis, the phonological constraints are ranked and violable by the phonetic forms of their underlying Representations in a tableau. This is a constraint-based competition system among a possibly infinite set of candidates (at least two) that are actually the potential surface forms of the input. The candidates minimally violate the constraints and the one that incurs the least serious violations interms of hierarchies of constraints, wins. Hence, logically, the violations of higher-ranked constraints are most serious and these violations first oust the concerned candidate from the competition and so on. An OT-style tableau, which uses harmony maximization as the criterion for optimality where the weights are in the top row and the rightmost column, provides the harmony values for the candidates. This framework can effectively analyze various aspects of phonological issues in a language in a comprehensive and systematic manner. An outline of the "classic" OT looks like as follows in (1):(1) Input $\rightarrow$ GEN $\rightarrow$ candidate set $\rightarrow$ EVAL (constraints) $\rightarrow$ Optimal Output.

\subsubsection{Feature Geometry}

As mentioned above, more and more researchers in OT are abolishing the idea of FG, proposing instead that properly ranked constraints alone can account for the data that FG had analyzed in derivational theory. A segment is not just an unorganized bundle of features, but that features have their own internal organization. This is well reflected in FG theory proposed by many researchers. The following is the FG model proposed by [1].

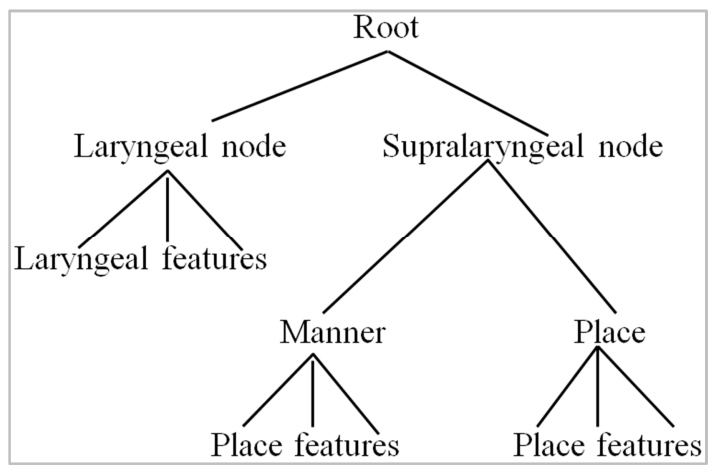

Figure 1. Feature Geometry Model [2].

As shown in the Figure 1 above, [2] recognizes that there are

Figure 1: Feature Geometry Model proposed by [1].

As shown in the Figure 1 above, [1] recognizes that three major feature groups, laryngeal features, manner features and place features, which Clements calls Class Nodes. He also assumes that the Manner Node and Place Node are combined together to make another internal hierarchical group under the Supra laryngeal Node. Clements uses the term tier to refer to the internal structural unit. Two tiers constitute a plane and phonological rules can be expressed as changes in association lines on specified planes. Similarly, Halle (1992) groups features according to the particular articulators that are involved in executing those features and comes up with the Laryngeal Node, the Place Node and the Soft Palate Node as shown in the following figure.

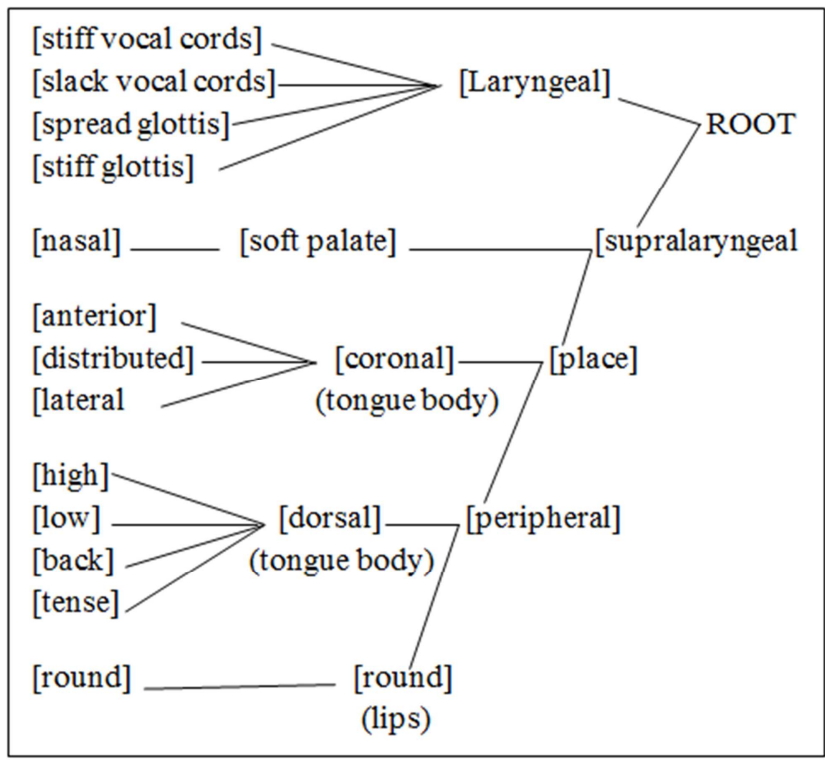

Figure 2. Feature Geometry Model Proposed by [2].

[2] FG, unlike Clements', does not have the Manner Node. Halle assumes that [nasal] and [lateral] are separate features that do not make up a natural class. Nonetheless, there is general agreement among researchers (including Halle and Clements) that there are at least a place node and a laryngeal node. [1] groups all the manner features together under a manner node and groups the manner node with the place node under the supra laryngeal node as shown in figure 3. Here are [1] manner features and the location of the manner node in FG.

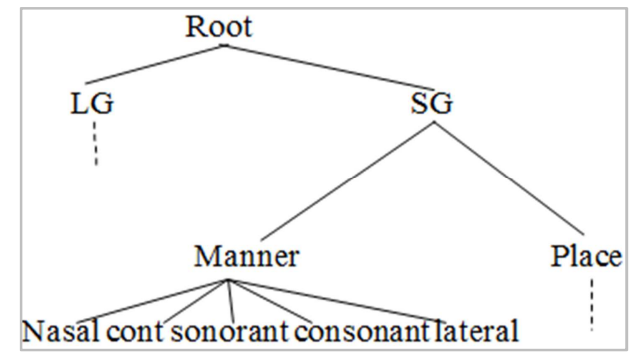

Figure 3. Manner feature and Node [1].

There are, however, several pieces of evidence which suggest that [cont] does act independently. Grimm's Law and Verner's Law were very productive in Germanic languages. The following is what Grimm and Verner suggest:

a. Grimm's Law: $p, t, k \rightarrow f, \Theta, x$

b. Verner's Law: $p, t, k \rightarrow f, s, x$. Both of these historical processes are analyzed quite simply as the addition of [cont], or spirantization. 


\section{Methodology}

The method of this research is analytical-descriptive. In order to conduct the study, six native speakers, selected from different age groups (from 30 to 50 year-old ones) and different educational levels were interviewed. The corpus primarily contains free conversation and life stories. Here, McCarthy's combination tableau was adapted. The combination tableau illustrates the ranking between constraints, as well as violation marks. In the tableau, each losing $(\mathrm{L})$ candidate is compared to the winning $(\mathrm{W})$ candidate in regards to each constraint. (W) denotes that the constraint in question prefers the winner rather than the losing candidate. This is why the winner satisfies the constraint, but the losing candidate does not, as specified by the violation mark $\left(^{*}\right)$, whereas the $(\mathrm{L})$ denotes that the given constraint is preferred the losing candidate rather than the winner $(\mathrm{W})$. The theory of Feature Geometry has succeeded in properly analyzing various phonological processes, such as assimilation and harmony, by attributing them to the internal structure of segments. With the advent of OT, however, such a structural account seems to be on the wane. Padgett, for example, assumes that most features are directly linked to the root node without constituting a hierarchical structure, and that constraint ranking for the most part determines phonological processes. In this paper, we shall compare these two theories by providing evidence from spirantization in Amharic.

\section{Result}

It was clearly observed from the data gathered that there is spirintization of consonants in Amharic. This phonological process which is found in the language can be represented by non-linear approach to phonology, specifically with Optimality Theory and Feature Geometry. Phonological representations may change from their lexical form to their surface or output forms. The important finding in many areas of phonology and morphology is that such changes are often conditioned by properties that hold of the surface or output forms in the language. These issues will be discussed in depth in the following sub-section of the article.

\section{Discussion}

\subsection{Spirantization in Optimality Theory}

In Amharic there is a process in which voiced stop consonant $/ \mathrm{b} /$ and voiceless stop consonant $/ \mathrm{k} /$ undergo spirantization in intervocalic position. They change to the fricative pair $[\beta]$ and $/ \mathrm{h} /$ in intervocalic place respectively. This process, besides simple words, also occurs between morphemes in a word and in a phrase. When the voiced stop $/ b /$ is located at the beginning of a word, this consonant will be pronounced [b], for example [bado] 'empty'. But when this word is located after a word with final vowel, intervocalic context is created for voiced stop consonant $/ \mathrm{b} /$ and it changes to counterpart fricative pair $[\beta]$. The word [bado] 'empty' in the compound word [hodäßado] 'empty stomached' is pronounced [ßado], because in Amharic, this consonant is located after a vowel. The voiceless stop $/ \mathrm{k} /$ becomes $[\mathrm{h}]$ inter-vocalically when affixes are added to the root. /näka/ 'touch' $\rightarrow$ [yinähal] 'he touches'.

Kenstowicz said that "postvocalic context is the most typical environment for the change from stop to fricative (spirantization). This is the environment where Tiberian Hebrew changes its stops [p, t, k] and [b, d, g] to the fricative $[f, \Theta, x]$ and $[v, \partial, \gamma]$. Jensen (2004:56) believes that: "lenition literally means weakening. It generally refers to a reduction in the degree of stricture in a sound, roughly along the scales of:

(a) stops $>$ flaps $>$ fricatives $>$ approximates $>\varnothing(b)$ voiceless aspirated $>$ plain voiceless $>$ voiced.

The scale in (a) varies by manner of articulation, while that in (b) involves glottal state." Examples of spirantization process, which has applied in Amharic dialects, are shown in the Table 2:

Table 2. Spirantization of $/ b /$ to $[\beta]$.

\begin{tabular}{lll}
\hline Amharic & & Gloss \\
\hline Pabäba & Paßäßa & flower \\
Paddis?aba & 2addis?aßa & Addis Ababa \\
kibirit & kißirit & matchbox \\
däbitär & däßitär & exercise book \\
zännäbä & zännäßä & it rained \\
galläbä & galläßä & he galloped \\
laba & laßa & feather \\
käbet & käßet & from house \\
\hline
\end{tabular}

McCarthy specifies lenition processes in optimality theory with [5] which is a combination of functionalism and structuralism. Kirchner said that "lenition patterns are expressed in terms of conflicts between the effort minimization constraint, LAZY, and on the other hand a class of lenition-blocking constraints. The lenition blocking constraints in turn are further divisible into "faithfulness" constraints (penalizing divergence from identity between underlying representation and corresponding surface form)." LAZY: minimize articulatory effort (i.e. biomechanical energy). Language-specific lenition patterns arise from LAZY, interacting with faithfulness constraints, within an Optimality Theoretic grammar. Spirantization, for example, is analyzed in terms of rankings where LAZY dominates IDENT (x). Under the opposite ranking, spirantization is blocked. The treatment of spirantization in the following tableau, in terms of conflict between LAZY and faithfulness, can trivially be extended to all manner of lenition phenomena. In the Table 3 we can see how LAZY acts in conflict with faithfulness constraint.

Table 3. Conflict of LAZY with Faithfulness Constraint.

\begin{tabular}{lll}
\hline Lenition degree & Effective causes & $\begin{array}{l}\text { Number of } \\
\text { stars }\end{array}$ \\
\hline Deletion & $\varnothing$ & $\varnothing$ (no star) \\
Voiced plosive & No deletion + plosive & $* *$ \\
Voiceless plosive & No deletion + plosive+ voiceless & $* * *$ \\
Voiced fricative & No deletion & $*$ \\
Voiceless fricative & No deletion + voiceless & $* *$ \\
Glide & No deletion & $*$ \\
\hline
\end{tabular}


In OT, allophonic variation is captured through the ranking of markedness constraints above faithfulness constraints. The relevant faithfulness constraint is IDENT-IO [continuant], and the relevant markedness constraints can be *VOICED STOP and $*[+$ son, + cont $]$. But for analyzing the data in table 2 we use three constraints: One is the markedness constraint LAZY and another is a faithfulness constraint IDENT [cont] and the other is IDENT [voice]. IDENT [cont]: Correspondent segments must have the same value of the feature [continuant]. Let $\mathrm{x}$ be a segment in the input and $y$ a segment in the output. If $x$ Ry, and $x$ is [+/- continuant], then $\mathrm{y}$ is [+/-continuant]. IDENT [voice]: Correspondent segments have identical values for the feature [voice]. Let $\mathrm{x}$ be a segment in the input, and $\mathrm{y}$ a segment in the output. If $x$ Ry and $x$ is [+/-voice], then $y$ is [+/-voice]. Tableau 1 presents analyses of the input /Rabäba/ 'flower'.

Table 4. Spirantization of analyses of the input/Pabäba/ 'flower'.

\begin{tabular}{llll}
\hline$/$ Rabäba/ & LAZY & IDENT [cont] & IDENT [voice] \\
\hline a. $\rightarrow[$ [aßäßa] & $*$ & $*$ & \\
b.[?apäpa] & $* * * \mathrm{~W}$ & $\mathrm{~L}$ & $* \mathrm{~W}$ \\
c.[?abäba] & $* * \mathrm{~W}$ & $\mathrm{~L}$ & \\
\hline
\end{tabular}

Candidate (a) in Table 4 is the winner since it has the least violation of constraint LAZY. About LAZY we can say that the more the process get closer to complete lenition which is the deletion, the less stars it gets. Since Candidate (c) is a stop consonant and it is not deleted, so it receives two stars. Also Candidate (b) is a voiceless stop and it is not deleted, so it violates three times from LAZY and receives 3 stars. In this tableau, if constraint IDENT [cont] was placed in higher ranking, the candidate (c) would be optimal. As a result LAZY have to have the highest ranking in this tableau. IDENT [cont] and IDENT [voice] are not in conflict with another. This ranking of constraints explains why our data is the optimal and winner candidate. The ranking is as follows: LA ZY $\gg$ IDENT [cont]; IDENT [voice]. The other kind of spirantization in Amharic dialect is the spirantization of $/ \mathrm{k} /$ to $[\mathrm{h}]$.

Table 5. Spirantization of $/ k /$ to $[h]$.

\begin{tabular}{lll}
\hline Amharic & & Gloss \\
\hline yinekal & yinehal & 'he touches' \\
yißokal & yißohal & 'it ferments' \\
aßakan & Paßahaj & 'extravagant' \\
yirekal & yirehal & 'he satisfies' \\
bäräkät & bärähät & 'blessing' \\
maßuhat & maßuhat & 'to knead' \\
Paläkäläkä & Palähälähä & 'he pants' \\
\hline
\end{tabular}

In analyzing the data in the Table 5, we can use three constraints: LAZY, IDENT [cont], IDENT [voice]. In the Table 6 the word /abahap/ will be analyzed.

Table 6. The analysis of the word /abahan/ 'extravagant'.

\begin{tabular}{llll}
\hline / abakaj / & IDENT [cont] & LAZY & IDENT [voice] \\
\hline$\rightarrow$ / abahap / & & $* *$ & $*$ \\
/abakan / & & $* * * \mathrm{~W}$ & $\mathrm{~L}$ \\
/ abayan / & $* \mathrm{~W}$ & $* \mathrm{~L}$ & $*$ \\
\hline
\end{tabular}

In the Table 6 , the candidate (c), have one violation of
LAZY constraint with changing the consonant $/ \mathrm{k} /$ to $[\mathrm{h}]$ and one violation of IDENT [voice] with changing the voice feature. As a result this candidate will be out of the competition at the beginning. The other candidate will continue the competition with regard to LAZY. The candidate (b) has three time violations of LAZY, because the candidate (b) is a voiceless plosive consonant and it has one step to deletion. So candidate (b) in comparative to candidate (a) which has two violations of LAZY is the loser and finally, the candidate (a) is the optimal candidate. We can see that just in this kind of spirantization, LAZY hasn't the highest ranking in the table 6 and the IDENT [voice] is the dominant constraint. The final ranking is as follows: IDENT [voice] $>>$ LAZY $>>$ IDENT [cont].

\subsection{Spirantizaition in the Feature Geometric Theory}

Let us now move on to an analysis within the gestural theory. As mentioned above, more and more researchers in OTare abolishing the idea of FG, proposing instead that properlyranked constraints alone can account for the data that FG had analyzed in derivational theory. A segment is not just an unorganized bundle of features, but that features have their own internal organization. This is well reflected in FG theory proposed by many researchers including [2], [8] and others.

As shown in Figure 1, Clements recognizes that there are three major feature groups, laryngeal features, manner features and place features, which Clements calls Class Nodes. He also assumes that the Manner Node and Place Node are combined together to make another internal hierarchical group under the Supra laryngeal Node. Clements uses the term tier to refer to the internal structural unit. Two tiers constitute a plane and phonological rules can be expressed as changes in association lines on specified planes. Similarly, [2] groups features according to the particular articulators that are involved in executing those features and comes up with the Laryngeal Node, the Place Node and the Soft Palate Node as was shown in Figure 2.

[2] FG, unlike [1], does not have the Manner Node. Halle assumes that [nasal] and [lateral] are separate features that do not make up a natural class. Nonetheless, there is general agreement among researchers (including Halle and Clements) that there are at least a place node and a laryngeal node. [1] groups all the manner features together under a manner node and groups the manner node with the place node under the supra laryngeal node as shown in Figure 3.

There are, however, several pieces of evidence which suggest that [cont] does act independently. Grimm's Law and Verner's Law, which were very productive in Germanic languages, illustrate the point:

a. Grimm's Law: $p, t, k \rightarrow f, \Theta, x b$. Verner's Law: $p, t, k \rightarrow$ f, s, x

Both of these historical processes are analyzed quite simply as the addition of [cont], or spirantization. According to the Figure3, all kinds of the spirantization in Amharic dialects can be analyzed. For example spirantization of $/ \mathrm{b} /$ to $[\beta]$ is shown below in Figure 4: 


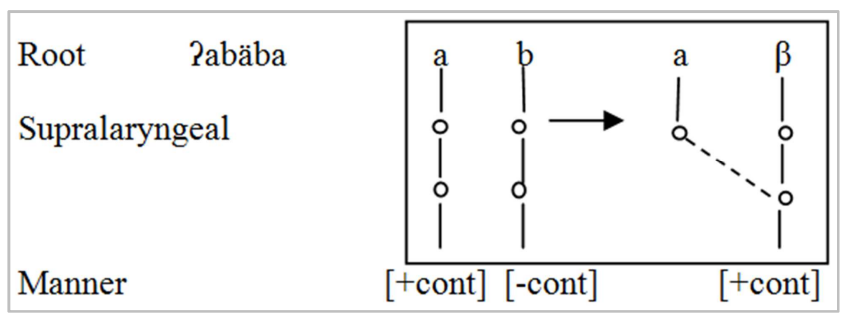

Figure 4. Spirantization of $/ b /$ to $[\beta]$.

Similar to the spirantization of $/ b /$ to $[\beta]$, spirantization of $/ \mathrm{k} /$ to $/ \mathrm{h} /$ which is specific to Schwa Amharic dialect can be represented by the following Figure 5 .

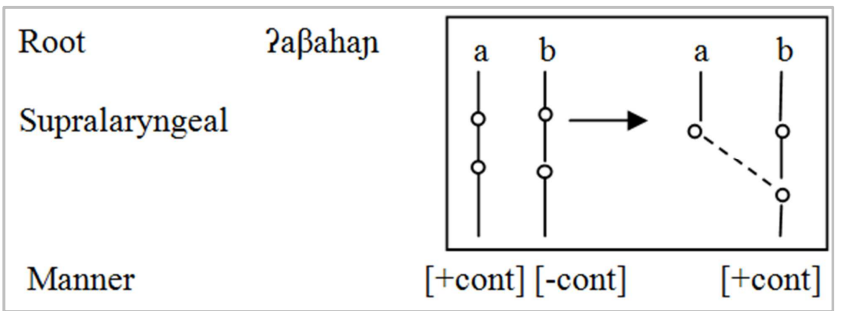

Figure 5. Spirantization of $/ k /$ to $[h]$.

\section{Conclusion}

In Amharic dialects, there are two consonants which engage in spirantization process. One is the voiced stop consonant $/ \mathrm{b} /$ which is changed to counterpart fricative pair $[\beta]$ in intervocalic place, the other is the voiceless stop consonant $/ \mathrm{k} /$, which is specific to Shewa dialect that changes to the fricative $[\mathrm{h}]$ in intervocalic place. [10] specifies lenition processes in optimality theory with Kirchner's theory which is a combination of functionalism and structuralism. Lenition patterns are expressed in terms of conflicts between the effort minimization constraint, LAZY, and on the other hand a class of lenition-blocking constraints. [5] Languagespecific lenition patterns arise from LAZY, interacting with faithfulness constraints, within an Optimality Theoretic grammar. Spirantization, for example, is analyzed in terms of rankings where LAZY dominates IDENT (x). Under the opposite ranking, spirantization is blocked. Also we saw that [1] recognizes that there are three major feature groups, laryngeal features, manner features and place features, which Clements calls Class Nodes. In spirantization process, in the manner node, [continuant] is added to a stop consonant, producing a fricative at the same place.

\section{Recommendation}

Work in Optimality Theory and Feature Geometry has opened up new lines of attack on familiar problems, disclosed unasked questions lost amid the descriptive plethora of early generative phonology, revived traditional insights and stances that could not previously be made sense of, problematized issues considered solved, and produced a significant body of results which move learnability, computation, and formal analysis into a central position in the phonological research program.

Thus, more comprehensive and in-depth research is recommended for less Amharic research is conducted using non-linear phonology compared to the studies on Amharic which are based on linear phonology.

\section{References}

[1] Clements, G. (1985). "The Geometry of Phonological Features", Phonology Year book 2, Cambridge university press, pp. 225-252.

[2] Halle, M. (1992). "Phonological Features" International Encyclopedia of Linguistics. Oxford, vol, 3, pp. 207-12.

[3] J. T. Jensen. (2004). Principles of Generative Phonology: An Introduction. John Benjamin's publishing Company.

[4] Kar, S. (2009). "Gemination in Bangla: An Optimalitytheoretic analysis". The Dhaka University, Journal of Linguistics. vol, 1 (2), pp. 87-114.

[5] Kirchner, R. (2001). An Effort Based-Approach to Consonant Lenition. Doctoral dissertation. New York: Rutledge.

[6] Lombardi, L. (1996). "Positional Faithfulness and Voicing Assimilation in Optimality Theory" Ms., University of Maryland, College Park.

[7] Lambordi. (1996). "Restrictions on direction of voicing assimilation: an OT account", University of Maryland, Working Papers in Linguistics, 1996b, 4,

[8] McCarthy, J. (1988). Feature geometry and Dependency: a review. Phonetica 45: 84-108. University of Massachusetts, Amherst, PP. 385-420.

[9] McCarthy, J. And Prince, A. (1995). "Faithfulness and Reduplicative Identity", Papers in Optimality Theory. In J. Beckman, S. Urbanczyk and L. WalshPP. 84-102.

[10] McCarthy, J. (2002). "A Thematic Guide to Optimality Theory", Cambridge: Cambridge University Press.

[11] McCarthy, J. (2008). "Doing Optimality Theory: Applying Theory to Data", Malden, MA: Blackwell Publishing. doi: 10. 1002/9781444301182,).

[12] Mulugeta Seyoum (2014). "The particle Pinde in Amharic", Studies in Ethiopian Languages. Addis Ababa, 3, PP. 83-95.

[13] Padgett, J. (1995). "Feature Classes", University of Massachusetts Occasional Papers, Papers in Optimality Theory, ed. by Jill N. Beckman, Laura Walsh Dickey and Suzanne Urbanczyk, GLSA.

[14] Prince, Alan and Paul Smolensky. 1993. Optimality Theory: Constraint Interaction in Generative Grammar. RuCCS-TR-2, Rutgers Center for Cognitive Science. New Brunswick: Rutgers University. ROA-XYZ.

[15] Sagey, E. (1986). The Representations of Features and Relations in Non-linear Phonology. Doctoral dissertation, MIT. 